\title{
Effects of Corticotropin-Releasing Factor on Neuronal Activity in the Serotonergic Dorsal Raphe Nucleus
}

Lynn G. Kirby, Ph.D., Kenner C. Rice, Ph.D., and Rita J. Valentino, Ph.D.

The present study examined the regional localization of corticotropin-releasing factor (CRF)-and 5-hydroxytryptamine (5-HT)-immunoreactive (IR) fibers within the rat dorsal raphe nucleus (DRN) using immunohistochemistry. Additionally, the effects of CRF, administered intracerebroventricularly $(0.1-3.0 \mu \mathrm{g})$ or intraraphe $(0.3-$ $30 \mathrm{ng})$, on discharge rates of putative 5-HT DRN neurons were quantified using in vivo single unit recording in halothane-anesthetized rats. CRF-IR fibers were present at all rostrocaudal levels of the DRN and exhibited a topographical distribution. CRF produced predominantly inhibitory effects on DRN discharge at lower doses and these effects diminished or became excitatory at higher doses. Inhibition of DRN discharge by CRF was attenuated by the nonselective CRF antagonist, DPheCRF $F_{12-41}$ and the $C R F-R 1$-selective antagonist, antalarmin, implicating the $C R F-R 1$ receptor subtype in these electrophysiological effects. The present findings provide anatomical and physiological evidence for an impact of CRF on the DRN-5HT system. [Neuropsychopharmacology 22:148-162, 1999] Published by Elsevier Science Inc.
KEY WORDS: Corticotropin-releasing hormone; 5-hydroxytryptamine; Stress; Immunohistochemistry; Antalarmin; DPheCRF $F_{12-41}$

Corticotropin-releasing factor (CRF) has a diverse range of physiological and behavioral effects, acting both as a neurohormone at the level of the anterior pituitary and as a neurotransmitter in brain. As a neurohormone, CRF initiates the release of adrenocorticotropic hormone which triggers the endocrine limb of the stress re-

From the Department of Psychiatry, Division of Stress Neurobiology (LGK, RJV), Medical College of Pennsylvania and Hahnemann University, Philadelphia, PA; and Laboratory of Medicinal Chemistry (KCR), National Institute of Diabetes and Digestive and Kidney Diseases, National Institute of Mental Health, Bethesda, MD.

Address correspondence to: Dr. Lynn G. Kirby, Department of Psychiatry; MS 403, Hahnemann University, Broad and Vine Streets, Philadelphia, PA 19102.

Received May 17, 1999; revised July 28, 1999; accepted August 3, 1999 sponse (Vale et al. 1983). Anatomical evidence of a widespread distribution of CRF-immunoreactive (IR) terminals and receptors throughout the brain (Chalmers et al. 1995; De Souza et al. 1985; Potter et al. 1994; Sakanaka et al. 1987; Swanson et al. 1983) provides support for the additional role of CRF as a brain neurotransmitter. An example of a potential neurotransmitter action of CRF is its action on the locus coeruleus (LC)-norepinephrine system. Intracerebroventricular (i.c.v.) or intracoerulear administration of CRF increases activity of LC neurons (Curtis et al. 1997; Page and Abercrombie 1999; Valentino et al. 1983) and stimulates NE release in terminal fields of the LC (Lavicky and Dunn 1993; Page and Abercrombie 1999; Smagin et al. 1995). Moreover, activation of LC neurons by certain physiological stimuli is attenuated by CRF antagonists administered into the LC (Curtis et al. 1994; Lechner et al. 1997).

Anatomical evidence suggests that CRF is also positioned to affect activity of the dorsal raphe nucleus 
(DRN)-5-hydroxytryptamine (5-HT) system. Thus, CRF receptor binding sites (De Souza et al. 1985) and mRNA (Chalmers et al. 1995; Potter et al. 1994) as well as CRF-IR terminals (Sakanaka et al. 1987; Swanson et al. 1983) are localized in the DRN, a primary site of 5-HT cell bodies projecting to the forebrain. Recent studies demonstrated that relatively low doses of CRF (administered i.c.v.) inhibit 5-HT release in two different terminal regions of the DRN (i.e., striatum and lateral septum), suggesting that the site of action of CRF effects on 5-HT release is at the level of the cell bodies in the DRN (Price and Lucki 1998; Price et al. 1998). Consistent with this, electrophysiological recordings indicated that a low dose of CRF (administered i.c.v.) that decreased extracellular levels of 5-HT in striatum also decreased DRN discharge rate (Price et al. 1998). In contrast to the effects of low doses of CRF, higher doses were found to not alter or to increase extracellular 5-HT levels in the lateral septum or striatum, respectively. The complex dose-related effects of CRF on 5-HT release could be a function of multiple CRF receptor subtypes within the DRN and/or different sites of action (cell bodies vs. terminals) of i.c.v. administered CRF.

The present study was designed to better characterize the effects of CRF on neuronal activity of putative 5-HT neurons of the DRN, with respect to dose-response and site of action. Additionally, because subnuclei within the DRN have different efferent and afferent connections, the topographical distribution of CRF fibers within the DRN was identified using immunohistochemical techniques.

\section{METHODS}

\section{Subjects}

Adult male Sprague-Dawley rats (Taconic Farms, Germantown, NY) initially weighing 250-300 g were housed 2-3 per cage on a 12-h light schedule (lights on at $07: 00$ a.m. in a temperature controlled $\left(20^{\circ} \mathrm{C}\right)$ colony room. Rats were given access to standard rat chow and water ad libitum. Animal protocols were approved by the Institutional Animal Care and Use Committee and were conducted in accordance with the NIH Guide for the Care and Use of Laboratory Animals.

\section{Immunohistochemistry}

Rats were deeply anesthetized with pentobarbital (60 $\mathrm{mg} / \mathrm{kg}$, intraperitoneal (i.p.) and perfused transcardially with $100 \mathrm{ml}$ of Ringer's lactate solution, followed by $1000 \mathrm{ml}$ of $4 \%$ paraformaldehyde in $0.1 \mathrm{M}$ phosphate buffer $\left(\mathrm{PB} ; 4^{\circ} \mathrm{C}, \mathrm{pH} 7.4\right)$. Brains were removed and stored in the same fixative solution for $90 \mathrm{~min}\left(4^{\circ} \mathrm{C}\right)$ and then overnight in a solution of $20 \%$ sucrose in $0.1 \mathrm{M} \mathrm{PB}$ containing $0.1 \%$ sodium azide $\left(4^{\circ} \mathrm{C}\right)$. Brains were rapidly frozen with $\mathrm{CO}_{2}$ and $30 \mu \mathrm{m}$ coronal sections cut on a cryostat. The sections were collected in $0.1 \mathrm{M} \mathrm{PB}$ ( $\mathrm{pH}$ 7.4).

Sections processed for dual immunohistochemistry to visualize $\mathrm{CRF}$ and 5-HT were first placed in a solution containing $0.75 \% \mathrm{H}_{2} \mathrm{O}_{2}$ in $0.1 \mathrm{M}$ phosphate buffered saline (PBS) for $20 \mathrm{~min}$. Sections were rinsed in PBS and incubated in a solution of rabbit anti-CRF antiserum (1:8000; Dr. W. Vale of the Salk Institute; lot c70) in PBS containing $0.6 \%$ Triton-X 100 (PBST), 0.5\% bovine serum albumin (BSA), and $0.1 \%$ sodium azide for $48 \mathrm{~h}$ at $4^{\circ} \mathrm{C}$. The sections were then rinsed in PBST-BSA and incubated in biotinylated donkey anti-rabbit IgG (1:200; Jackson Labs, West Grove, PA) in PBST-BSA for $90 \mathrm{~min}$ followed by rinses in PBST-BSA. Finally, sections were incubated for $90 \mathrm{~min}$ in avidin-biotin complex (ABC Elite kit; Vector Labs, Burlingame, CA), rinsed in PBS, and reacted with Vectastain (VECTOR SG substrate kit; Vector Labs) containing $\mathrm{H}_{2} \mathrm{O}_{2}$ for a blue reaction product.

Prior to incubation in anti-5-HT antibody, the sections were immersed in $0.75 \% \mathrm{H}_{2} \mathrm{O}_{2}$ for $20 \mathrm{~min}$ and rinsed in PB. They were incubated in rabbit monoclonal anti-5-HT antibody (1:30,000; Incstar Co., Stilwater, $\mathrm{MN}$ ) in PBST for $48 \mathrm{~h}$ at $4^{\circ} \mathrm{C}$ and then rinsed in PBST and incubated in secondary donkey anti-rabbit antiserum (1:500; Jackson Labs, West Grove, PA) in PBST at room temperature for $90 \mathrm{~min}$. After rinsing in PBST, the sections were incubated in rabbit PAP (1:500; DAKO Corp., Carpinteria, CA) in PBST for $90 \mathrm{~min}$ at room temperature, rinsed in PBST followed by $\mathrm{PB}$, and visualized by a reaction in 3-3' diaminobenzidine (DAB; Sigma Chemical Co., St. Louis, $\mathrm{MO}$ ) and $\mathrm{H}_{2} \mathrm{O}_{2}$ in $0.1 \mathrm{M}$ $\mathrm{PB}$ for a brown reaction product. Ultimately, the sections were rinsed in PB and mounted on glass gelatinized slides, dehydrated in a series of alcohols and coverslipped with Permount. Visualization was performed using a Leitz microscope and photographs were taken with Kodak Ektar 25 film.

\section{Electrophysiology-Surgery}

The procedures used for recording DRN discharge were similar to those previously described (Price et al. 1998). Male Sprague-Dawley rats were anesthetized with $2 \%$ halothane-in-air mixture administered through a nose cone and maintained at $1 \%$ throughout the experiment. Body temperature was maintained at $36-37^{\circ} \mathrm{C}$ with a feedback-controlled heating pad. Subjects were positioned in a stereotaxic instrument with blunt ear bars with the head in the horizontal plane. The skull was exposed and a hole, centered on the midline at 7.5 $\mathrm{mm}$ caudal to bregma was drilled to expose the dura and the associated superficial transverse and saggital sinuses. The saggital sinus was ligated, transected, and reflected to allow for a midline approach to the DRN 
with minimal blood loss. For i.c.v. administration, a hole was drilled $1.5 \mathrm{~mm}$ lateral to midline and $1.0 \mathrm{~mm}$ caudal to bregma and a 26 gauge stainless steel cannula lowered into the lateral ventricle to a depth of $5.6 \mathrm{~mm}$ ventral from the skull surface.

\section{Recording and Microinfusion}

Single unit DRN discharge was recorded with single- or multi-barrel glass micropipettes $(2-4 \mu \mathrm{m}$ tip diameter recording electrode, 4-7 MOhm) filled with $2 \%$ Pontamine Sky Blue (PSB) dye in $0.5 \mathrm{M}$ sodium acetate.

For intraraphe microinfusions, double- or triple-barrel micropipettes consisting of a recording pipette glued adjacent to infusion pipettes were used. Microinfusion pipettes (20-50 $\mu \mathrm{m}$ diameter tip) were angled at approximately $30-45^{\circ}$ with tips adjacent to the tip of the recording pipette but $80-120 \mu \mathrm{m}$ dorsal. The microinfusion pipettes were filled with CRF, DPheCRF ${ }_{12-41}$ or artificial cerebrospinal fluid (ACSF) and connected by polyethylene tubing to a controlled source of pressure (Picospritzer; General Valve, Inc., Fairfield, NJ). Microinfusions were made by applying short pulses (20-50 $\mathrm{ms}$ ) of small magnitudes of pressure (20-30 psi) at the rate of $0.1-0.5 \mathrm{~Hz}$ (manual trigger) until the appropriate volume was infused. The microinfusion pipette was calibrated such that known volumes could be administered $(1 \mathrm{~mm}$ displacement $=60 \mathrm{nl})$.

The micropipette was placed on the midline $7.5 \mathrm{~mm}$ caudal to bregma and lowered towards the DRN with a micromanipulator. Microelectrode signals passed from a preamplifier to filters and additional amplifiers. Impulse activity was monitored on an oscilloscope and loudspeaker. When stable, unitary action potentials were isolated, a window discriminator was used to convert the occurrence of each action potential into digital pulses, which were led into a Gateway computer via a CED 1401 Plus interface (Cambridge Electronic Design, Cambridge, UK) using Spike-2 software for on-line visualization and storage and off-line analysis. DRN neurons were tentatively identified on the basis of characteristic firing patterns described previously (see Baraban and Aghajanian 1980): a slow (0.5-2.5 Hz), regular firing rate and biphasic action potentials of 1.0-3.0 ms duration. DRN cells were typically encountered between 5.0 and $6.0 \mathrm{~mm}$ ventral to brain surface.

DRN spontaneous discharge was recorded for at least 10 min prior to drug administration. Peptides or vehicle were injected i.c.v. in a volume of $3.0 \mu$ l over a $30 \mathrm{sec}$ period or directly into the DRN (adjacent to the recording electrode) in a volume of $30 \mathrm{nl}$ over a 1-2 min period. Neuronal activity was recorded for at least $10 \mathrm{~min}$ after CRF administration. For antagonist studies, antalarmin was administered (30 mg/kg, i.p.) $30 \mathrm{~min}$ prior to CRF and $\mathrm{DPheCRF}_{12-41}(10 \mathrm{ng})$ was microinfused into the DRN
15 min prior to CRF. The dose of antalarmin and pretreatment time were based on pilot studies examining antagonism of CRF activation of LC neurons by antalarmin.

In these pilot studies, $20-30 \mathrm{mg} / \mathrm{kg}$ (i.p.) was equivalent to $3 \mu \mathrm{g} \mathrm{DPheCRF}_{12-41}$ (i.c.v.). Note: antalarmin was administered systemically only because it could not be easily administered by micropipette. Only one dose of CRF or one CRF/CRF antagonist combination was tested on a single cell and only one cell tested in an individual rat. At the end of the experiment, 8-hydroxy2(di-n-propylamino)tetralin (8-OH-DPAT; $0.025 \mathrm{mg} /$ $\mathrm{kg}$, subcutaneous (s.c.)) was administered and discharge recorded for an additional $5 \mathrm{~min}$.

\section{Histology}

After the experiment, the recording site was marked by iontophoresis of PSB from the recording pipette $(-12$ $\mathrm{mA}, 10 \mathrm{~min})$. For experiments involving i.c.v. administration of CRF, $5 \mu \mathrm{l}$ of neutral red dye was injected through the i.c.v. cannula. Rats were injected with pentobarbital $(100 \mathrm{mg} / \mathrm{kg}$, i.p.) and perfused transcardially with PB. Brains were removed and first cut to visualize neutral red dye in the ventricular system and then frozen at $-70^{\circ} \mathrm{C}$. Frozen $40 \mu \mathrm{m}$-thick coronal sections cut on a cryostat were mounted on gelatinized glass slides and stained with neutral red for localization of the PSB spot. For i.c.v. experiments, only data from rats which had neutral red dye in the ventricular system and electrode placements in the DRN were used in the analysis. For all other experiments, only data from rats which had electrode placements in the ventromedial subdivision of the DRN were used in the analysis (e.g. Figure 6).

\section{Data Analysis}

DRN discharge was recorded on-line on a Cambridge Electronics Design 1401 data analysis system using Spike-2 software. The mean discharge rate determined over five 1-min intervals prior to drug administration was taken as the mean basal discharge rate with subsequent rates expressed as a percentage of this mean. Mean baseline DRN spontaneous discharge rates of various treatment groups were compared by a one-way factorial analysis of variance (ANOVA).

Differences between time course data of different treatment groups were compared to vehicle controls by two-way, repeated measures ANOVA. The effect of a specific dose of drug or vehicle on DRN discharge was analyzed by one-way, repeated measures ANOVA.

The area under the time-effect curve (AUC) was calculated for individual subjects to summarize the overall effect of a specific dose of drug or vehicle. Mean AUC values were compared between treatment groups by one-way factorial ANOVA. Mean AUC values associ- 
ated with specific drug doses were compared to vehicle controls by unpaired Student's t-test, two-tailed.

\section{Drugs}

Ovine CRF and $\mathrm{DPheCRF}_{12-41}$ were generously supplied by Dr. Jean Rivier of the Clayton Foundation Laboratories for Peptide Biology, The Salk Institute, La Jolla, CA. The peptides were dissolved in water to make a $1.0 \mathrm{mg} / \mathrm{ml}$ solution. Aliquots of this solution (10 $\mu l)$ were concentrated using a Savant Speed Vac concentrator. The resulting $10 \mu \mathrm{g}$ aliquots were stored at $-70^{\circ} \mathrm{C}$ and dissolved in ACSF [ $\mathrm{NaCl}(122 \mathrm{mM}), \mathrm{KCl}(3.1$ $\mathrm{mM}), \mathrm{NaH}_{2} \mathrm{PO}_{4}(400 \mu \mathrm{M}), \mathrm{MgSO}_{4}(1.2 \mathrm{mM}), \mathrm{CaCl}_{2}(1.3$ $\mathrm{mM}), \mathrm{NaHCO}_{3}(25 \mathrm{mM})$, glucose $\left.(10 \mathrm{mM})\right]$ on the day of the experiment.

Antalarmin (Kenner C. Rice, Laboratory of Medicinal Chemistry, NIH/NIDDK, Bethesda, MD) was suspended in a solution containing $24 \%$ cremaphor and $6 \%$ ethanol and injected i.p. (30 mg/ $\mathrm{kg})$ in a volume of 1.0 $\mathrm{ml} / \mathrm{kg}$.

\section{RESULTS}

\section{CRF and 5-HT Immunoreactivity within the DRN}

Although CRF-IR fiber labeling was apparent throughout the DRN, the distribution of fibers within the DRN varied as a function of the rostro-caudal level. At caudal levels, CRF-IR fibers were most dense in the dorsal subdivision (periventricular) and lateral wings of the DRN (Figures 1A and 2A, left panel). Proceeding rostrally, CRF-IR fibers became more dense in the ventromedial subdivision of the DRN, and were less apparent dorsally (Figure 1B and Figure 2, middle panels). Finally, at more rostral levels, CRF-IR fibers were most dense in the intrafascicular region (Figure $1 \mathrm{C}$ and Figure 2, right panels). These fibers were varicose and appeared to be in close proximity with 5-HT-labeled neurons, as well as non-labeled neurons (Figure 2B, left panel). 5-HT-IR neurons were most dense in the ventromedial cell subdivision of the DRN (Figure 2A).

\section{Effects of i.c.v. CRF or Vehicle on DRN Discharge}

DRN activity was recorded from 50 neurons in rats subsequently administered CRF (0.1-3.0 $\mu$ g, i.c.v.) or vehicle. DRN spontaneous discharge rate in the different treatment groups ranged from $0.92 \mathrm{~Hz}$ to $1.38 \mathrm{~Hz}$ with a mean of $1.18 \pm 0.07 \mathrm{~Hz}$. There were no significant differences in basal DRN discharge rates between different treatment groups. At the end of each experiment, 8-OHDPAT, an agonist at inhibitory $5-\mathrm{HT}_{1 \mathrm{~A}}$ autoreceptors, was administered $(0.025 \mathrm{mg} / \mathrm{kg}$, s.c. $)$ to pharmacologically verify the serotonergic nature of the recorded cell. 8-OH-DPAT typically shut off cell firing within 1 to $3 \mathrm{~min}$.

The i.c.v. administration of vehicle did not alter DRN discharge rate. In contrast, administration of CRF (0.1$3.0 \mu$ g, i.c.v.) had predominantly inhibitory effects on DRN discharge (Figure 3A). The magnitude and time course of CRF effects were often variable within a treatment group. For example, the response to $1 \mu \mathrm{g} C R F$ was a rapid onset, long duration inhibition (35-50\%) in three of eight cells, gradual onset inhibition (36-73\%) in two of eight cells, a gradual, near complete inhibition $(96 \%)$ in one neuron, brief excitation followed by inhibition $(40 \%)$ in another neuron and no response in one neuron. Both the 0.1 and $1.0 \mu \mathrm{g}$ dose of CRF decreased DRN discharge rate from baseline over the time of recording $[\mathrm{F}(20,160)=1.88, p<.05$ and $\mathrm{F}(20,140)=1.96$, $p<.05$, respectively].

Comparison of the effects of vehicle vs. $1 \mu \mathrm{g}$ CRF on DRN discharge showed a statistically significant effect of treatment $[\mathrm{F}(1,15)=4.53, p=.05]$ but no significant interaction. Comparison of the effects of vehicle vs. 0.1, 0.3 , or $3.0 \mu \mathrm{g}$ CRF showed no statistically significant effects of treatment or interaction.

Figure 3B summarizes the results shown in Figure $3 \mathrm{~A}$ using the area under the curve describing the relationship between time and effect to illustrate an overall
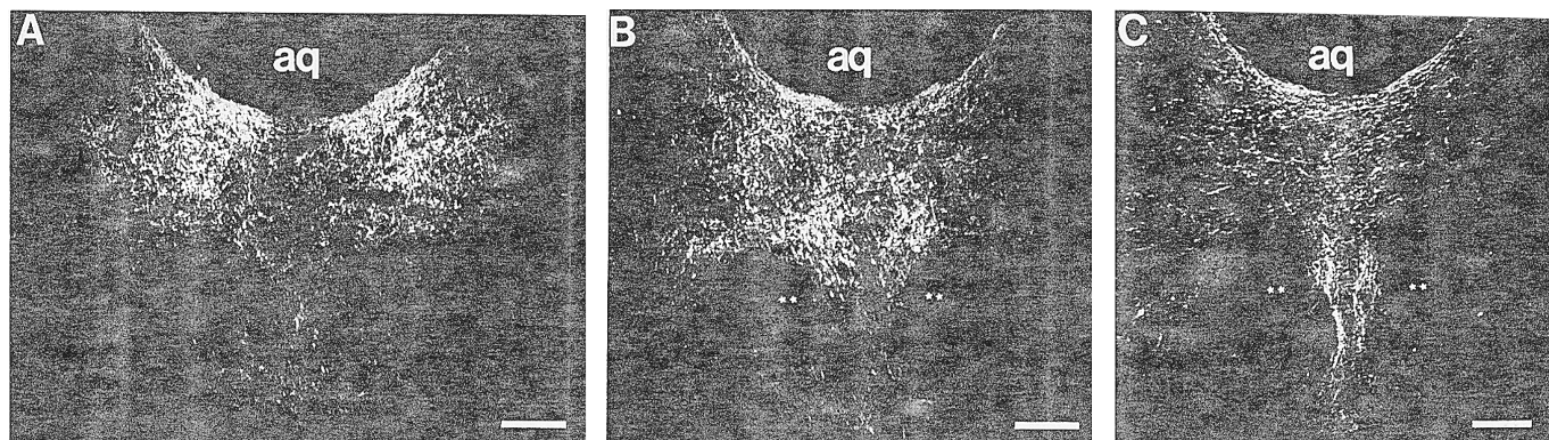

Figure 1. Darkfield photomicrographs of $30-\mu \mathrm{m}$ coronal sections through the rat DRN proceeding caudal to rostral (A to C) showing the distribution of CRF-IR fibers. Asterisks in B and C indicate the location of the medial longitudinal fasciculus. The cerebral aqueduct is indicated by aq. Dorsal is at the top. Calibration bars represent $200 \mu \mathrm{m}$. 
A
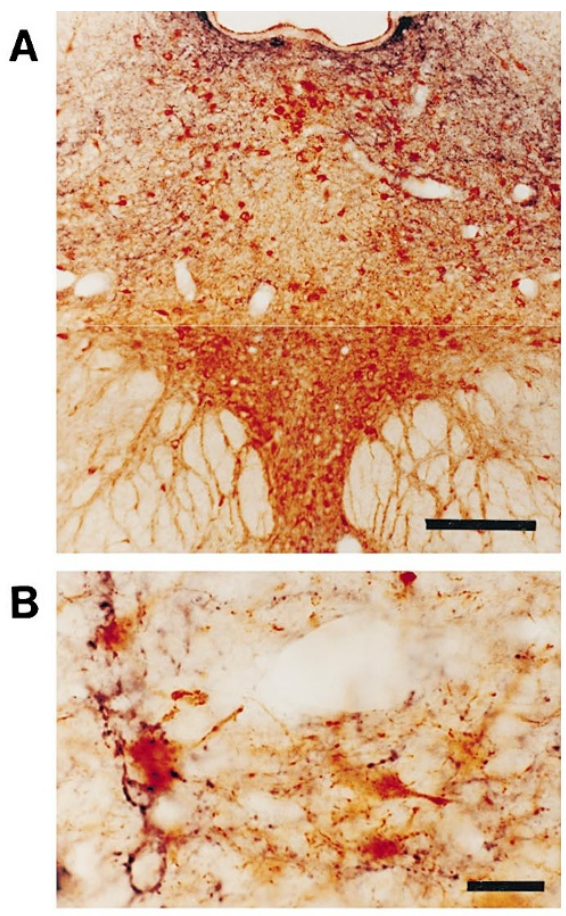
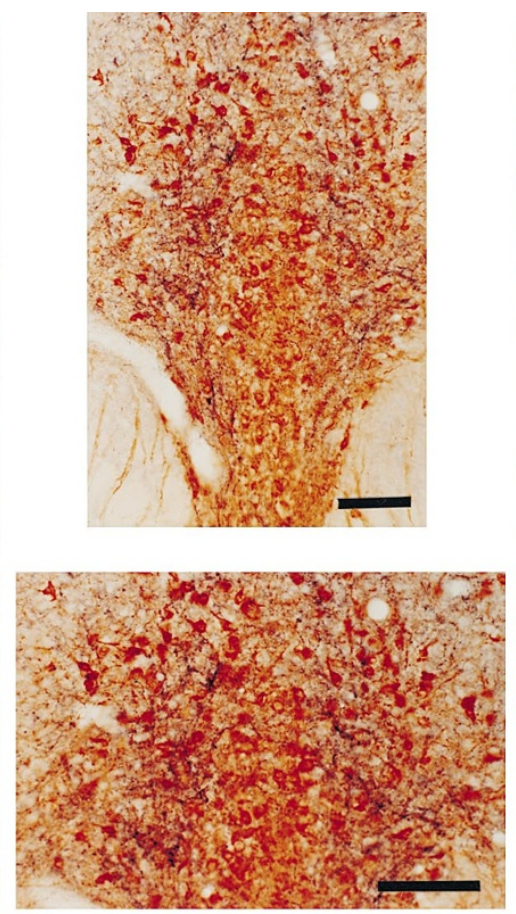
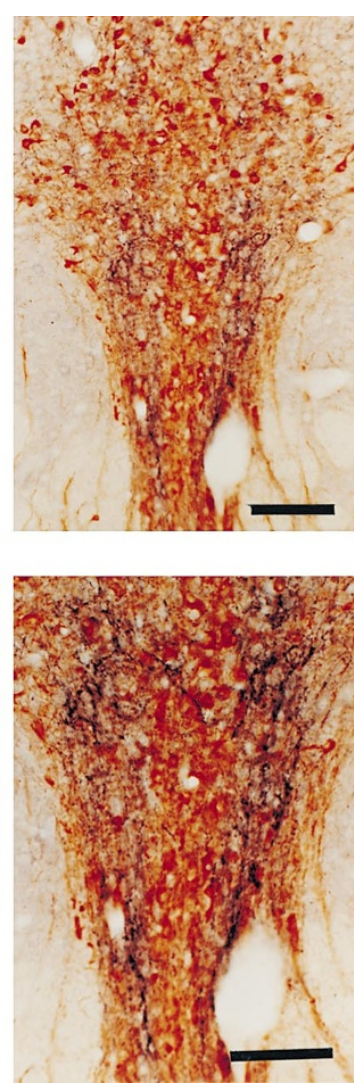

Figure 2. Brightfield photomicrographs of 30- $\mu \mathrm{m}$ thick coronal sections through the rat DRN. Sections were double labeled to visualize 5-HT-immunoreactivity (brown) and CRF-immunoreactivity (blue). (A) Sections are shown at three different levels proceeding caudal to rostral (left to right). (B) The leftmost panel is from a section at the same caudal level as shown in panel A above (left-hand panel) and shows CRF-IR varicosities adjacent to 5-HT-IR neurons. Additionally, a CRF-IR fiber appears to be surrounding an unlabeled neuron in the vicinity. The middle and right-hand panels are higher magnification photomicrographs of the same sections shown in panel A above, to illustrate the density of the varicose CRF-IR fibers in the nucleus at these levels. Dorsal is at the top. Calibration bars represent $200 \mu \mathrm{m}$ (A, left panel), $25 \mu \mathrm{m}$ (B, left panel), or $100 \mu \mathrm{m}$ (middle and right panels).

effect of each dose of CRF or vehicle on DRN discharge. There was a tendency towards a U-shaped dose-response function for CRF inhibition of DRN discharge. A comparison of the area under the curve values associated with individual doses of CRF vs. vehicle demonstrated a statistically significant difference between vehicle and $1.0 \mu \mathrm{g}$ CRF $[t(15)=2.10, p=.05]$.

A posthoc analysis of CRF effects for cells located in different subnuclei of the DRN indicated a topographic pattern to CRF-responsivity. CRF responses were divided into three categories: increase (greater than $20 \%$ elevated discharge above baseline for at least three successive minutes), decrease (greater than $20 \%$ reduced discharge below baseline for at least three successive minutes), and no change.

Cells located in the ventromedial subdivision of the DRN were primarily inhibited by CRF. Of 28 cells in this subdivision, discharge rate was decreased in 17 $(60.7 \%)$, increased in four $(14.3 \%)$, and unaffected in seven $(25.0 \%)$. In contrast, cells located in the dorsome- dial and lateral wing subdivisions of the DRN had more heterogeneous responses to CRF. Of 13 cells located in these subdivisions, six $(46.1 \%)$ were inhibited by CRF, four (30.8\%) were activated, and three (23.1\%) were unaffected. As a result of this finding, subsequent experiments were conducted on cells located in the ventromedial subdivision of the DRN.

\section{Effects of Intraraphe CRF or Vehicle on DRN Discharge}

Neuronal discharge was recorded from 57 neurons in the ventromedial/intrafasicular region of the DRN of rats subsequently administered CRF (0.3-30 ng, intraraphe) or vehicle. DRN spontaneous discharge rate ranged from 0.90 to $1.16 \mathrm{~Hz}$, with a mean of $1.01 \pm 0.07$. There were no significant differences in basal DRN discharge rates between these treatment groups.

When administered directly into the DRN (see Fig- 
A

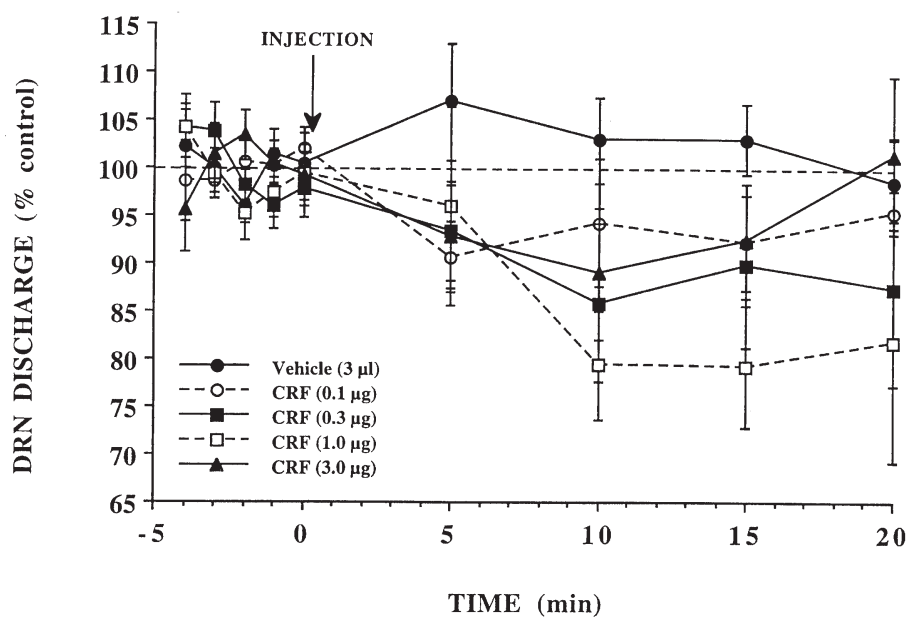

B

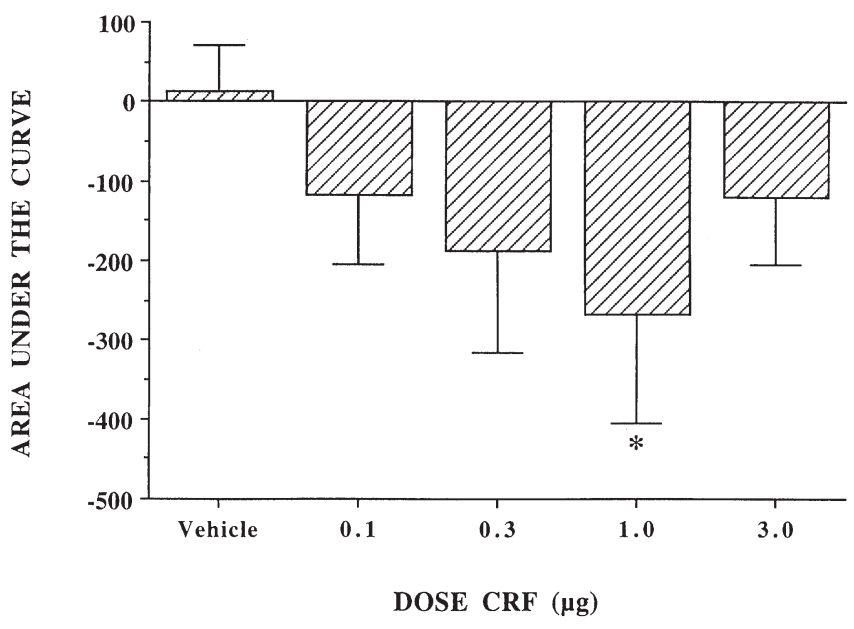

Figure 3. Effects of i.c.v. injection of CRF (0.1-3.0 $\mu \mathrm{g})$ or vehicle $(3.0 \mu \mathrm{l})$ on the discharge rate of putative 5-HT neurons in the DRN. (A) The abscissa indicates time before and after injection, indicated by the arrow, which occurred at 0 . The ordinate indicates the mean discharge rate expressed as a percentage of the mean rate determined over $5 \mathrm{~min}$ prior to injection. Shown are the effects of CRF: $0.1 \mu \mathrm{g}$ (open circles, dashed line), $0.3 \mu \mathrm{g}$ (closed squares, solid line), $1.0 \mu \mathrm{g}$ (open squares, dashed line), $3.0 \mu \mathrm{g}$ (closed triangles, solid line), and vehicle (closed circles, solid line). (B) Bars represent the area under the curve describing the time-effect relationship to illustrate the overall effect of each dose of CRF or vehicle on DRN neuronal discharge. Each data point is the mean of at least 8 determinations \pm 1 S.E.M. value. The asterisk indicates a significant difference from vehicle controls by unpaired Student's $t$-test $(p<.05)$. ure 6 for representative microinjection sites), CRF (0.3$10 \mathrm{ng}$ ) caused a dose-dependent decrease in DRN discharge that was apparent within minutes after the injection with an average peak by 9-10 min after injection (see Figure 5A). Figure 4 shows representative recordings of the activity of individual neurons following intraraphe administration of $0.3,3.0$, and $30 \mathrm{ng}$ CRF. CRF $(1.0,3.0$ and $10 \mathrm{ng})$ produced statistically significant decreases in discharge rate from baseline $[\mathrm{F}(11,99)=2.36$, $p<.05 ; \mathrm{F}(11,77)=4.00, p<.01 ;$ and $\mathrm{F}(11,66)=1.97, p<$ .05 , respectively].

Comparison of the effects of vehicle vs. $3.0 \mathrm{ng}$ CRF on DRN discharge showed a statistically significant effect of treatment $[\mathrm{F}(1,16)=5.71, p<.05]$ and interaction $[\mathrm{F}(11,176)=2.02, p<.05]$. Comparison of the effects of vehicle vs. $0.3 \mathrm{ng}, 1.0 \mathrm{ng}$, or $10 \mathrm{ng}$ CRF on DRN discharge showed no statistically significant effect of treatment or interaction.

Injection of vehicle or $30 \mathrm{ng} \mathrm{CRF}$ rapidly and transiently increased the discharge rate of DRN neurons above preinjection baseline $[\mathrm{F}(11,99)=6.13, p<.01$ and $\mathrm{F}(11,110)=2.25, p<.05$, respectively] (Figures $4 \mathrm{C}$ and 5B). A comparison of the effects of vehicle vs. $30 \mathrm{ng}$ CRF on DRN discharge showed no significant effect of treatment or interaction.

Figure 5C summarizes the results shown in Figures $5 \mathrm{~A}$ and $5 \mathrm{~B}$ using area under the curve calculations to illustrate the overall effect of each dose of CRF or vehicle on DRN discharge. CRF (3.0 ng) produced a statistically significant decrease compared to vehicle $[t(16)=2.43, p<$ $.05]$, according to a Student's $t$-test for independent samples. There was a tendency for the effect produced by $30 \mathrm{ng}$ CRF to be greater than vehicle, but this was not statistically significant.

Figure 6 shows the representative plots at a rostral (upper panel) and caudal level (lower panel) of the DRN from subjects administered 3.0 ng CRF to illustrate the location of cells within the ventromedial subdivision of the DRN that were selected for electrophysiological recording. 

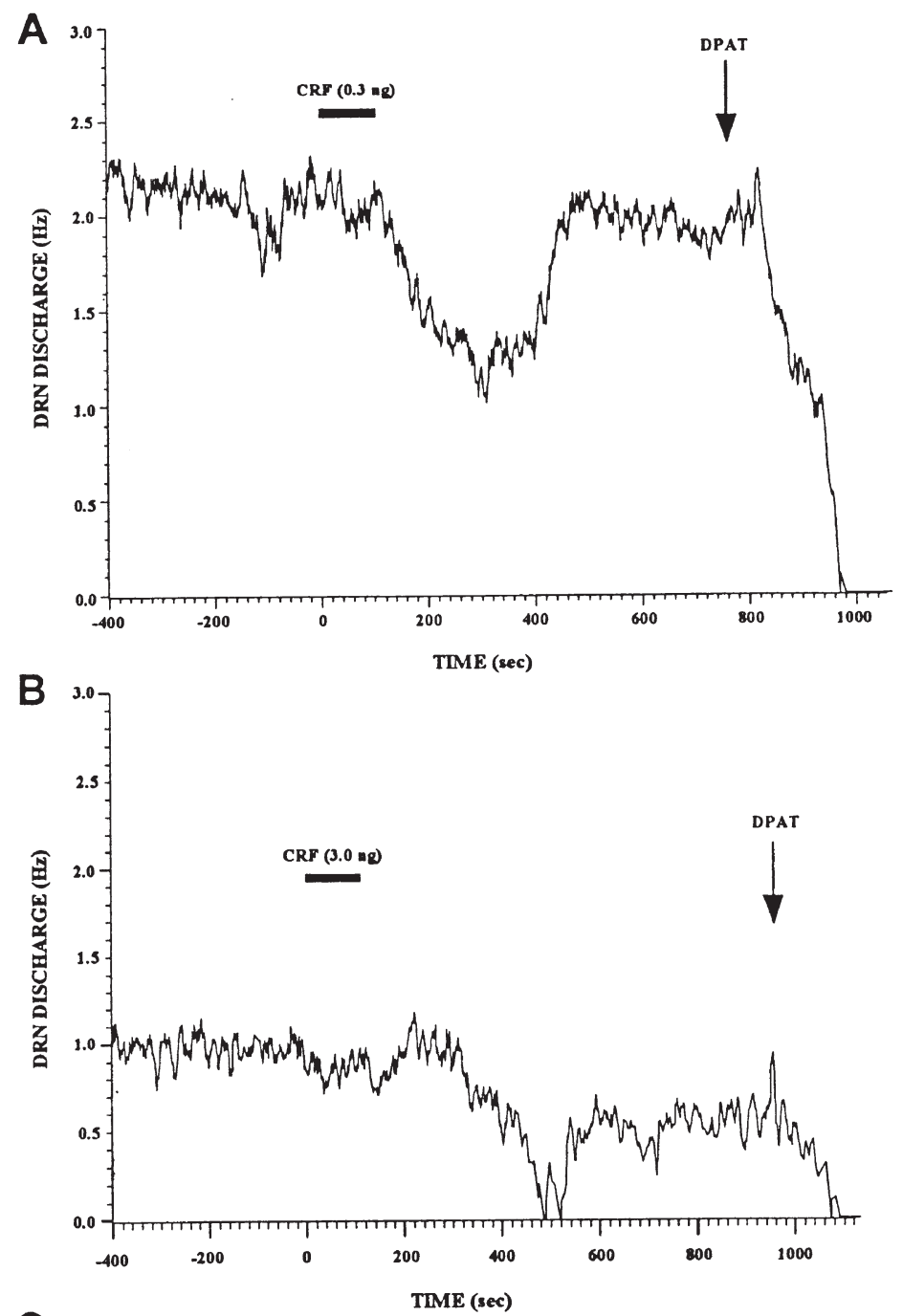

Figure 4. Examples of the effect of intraraphe infusion of CRF on the discharge rate of DRN neurons. CRF (0.3 ng, (A) $3.0 \mathrm{ng}$, (B) $30 \mathrm{ng}$, (C) was infused over a 2-min period as indicated by the bar and 8-OH-DPAT $(0.025 \mathrm{mg} / \mathrm{kg}$, s.c. $)$ was injected at the end of the experiment as indicated by the arrow. In the example shown in Figure 4A, 0.3 ng CRF inhibited DRN discharge, although the group effect of this dose was not significant (see Figure 5).

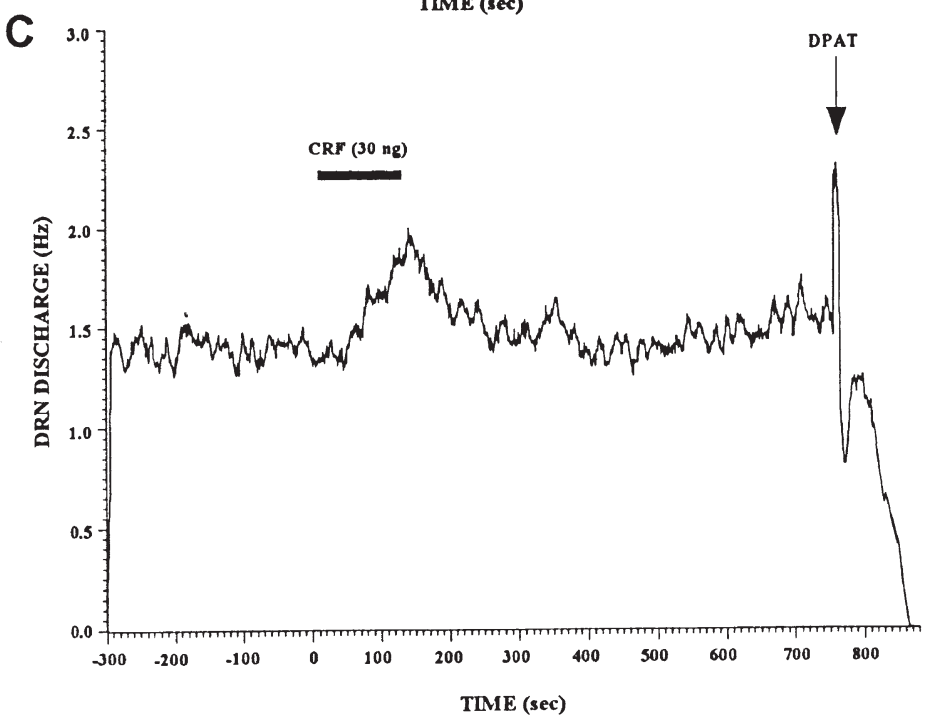

\section{Effects of CRF Antagonists}

DRN activity was recorded from 27 neurons in rats subsequently administered CRF following pretreatment with a CRF antagonist. DRN spontaneous discharge rate in the different treatment groups ranged from 0.42 $\mathrm{Hz}$ to $1.69 \mathrm{~Hz}$ with a mean of $0.94 \pm 0.07 \mathrm{~Hz}$. Basal DRN discharge did not differ between groups administered 3.0, 10, or $30 \mathrm{ng}$ CRF with or without antalarmin 
A

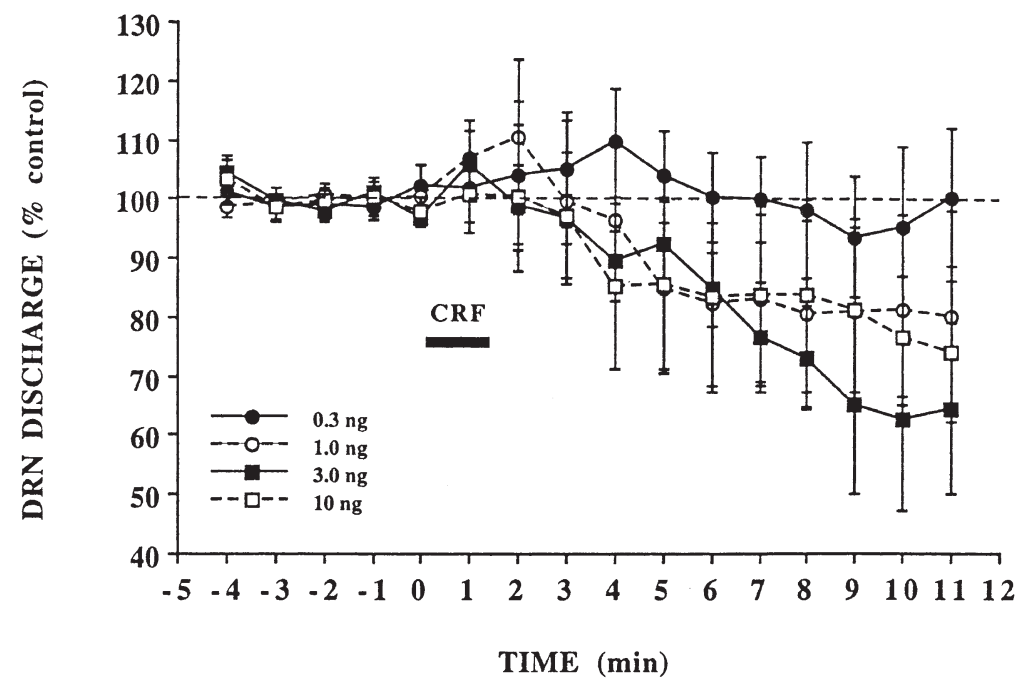

B

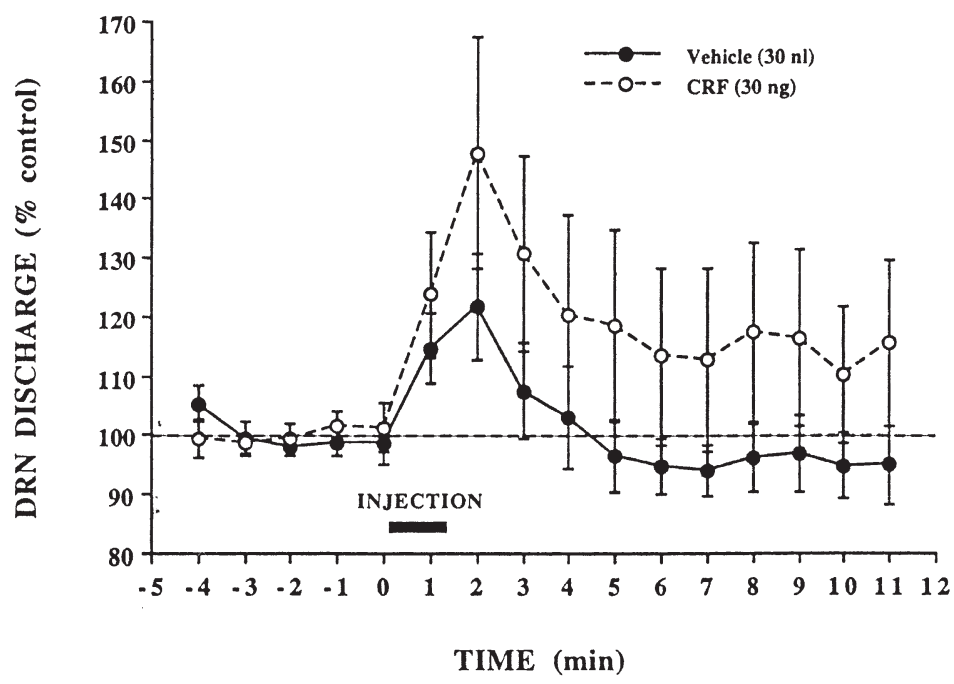

C

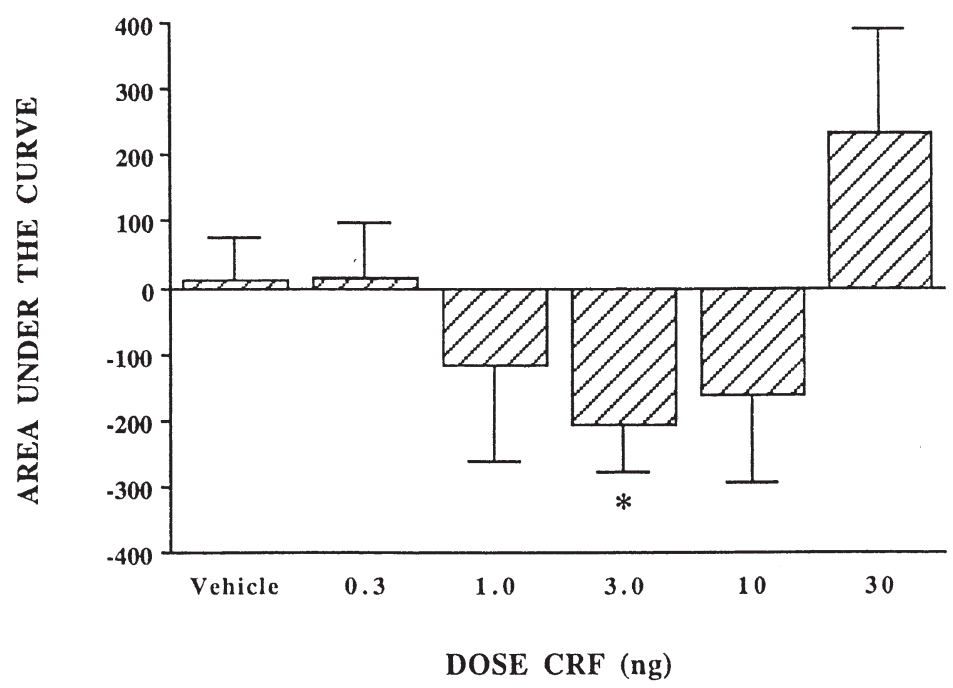

Figure 5. Effect of intraraphe infusion of CRF (0.3-30 ng) or vehicle $(30 \mathrm{nl})$ on the discharge rate of putative 5-HT neurons in the DRN. (A) The abscissa indicates the time before and after microinfusion, indicated by the bar, which began at 0 . The ordinate indicates the mean discharge rate expressed as a percentage of the mean rate determined over $5 \mathrm{~min}$ prior to injection. Shown are the effects of CRF: $0.3 \mathrm{ng}$ (closed circles, solid line), $1.0 \mathrm{ng}$ (open circles, dashed line), 3.0 ng (closed squares, solid line), and $10 \mathrm{ng}$ (open squares, dashed line). (B) Effects of CRF (30 ng) (open circles, dashed line) or vehicle (closed circles, solid line). Abscissa and ordinate as in (A). (C) Bars represent the area under the curve describing the timeeffect relationship to illustrate the overall effect of each dose of CRF or vehicle on DRN neuronal discharge. Each data point is the mean of at least 7 determinations \pm 1 S.E.M. value. The asterisk indicates a significant difference from vehicle controls by unpaired Student's t-test $(p<.05)$. 

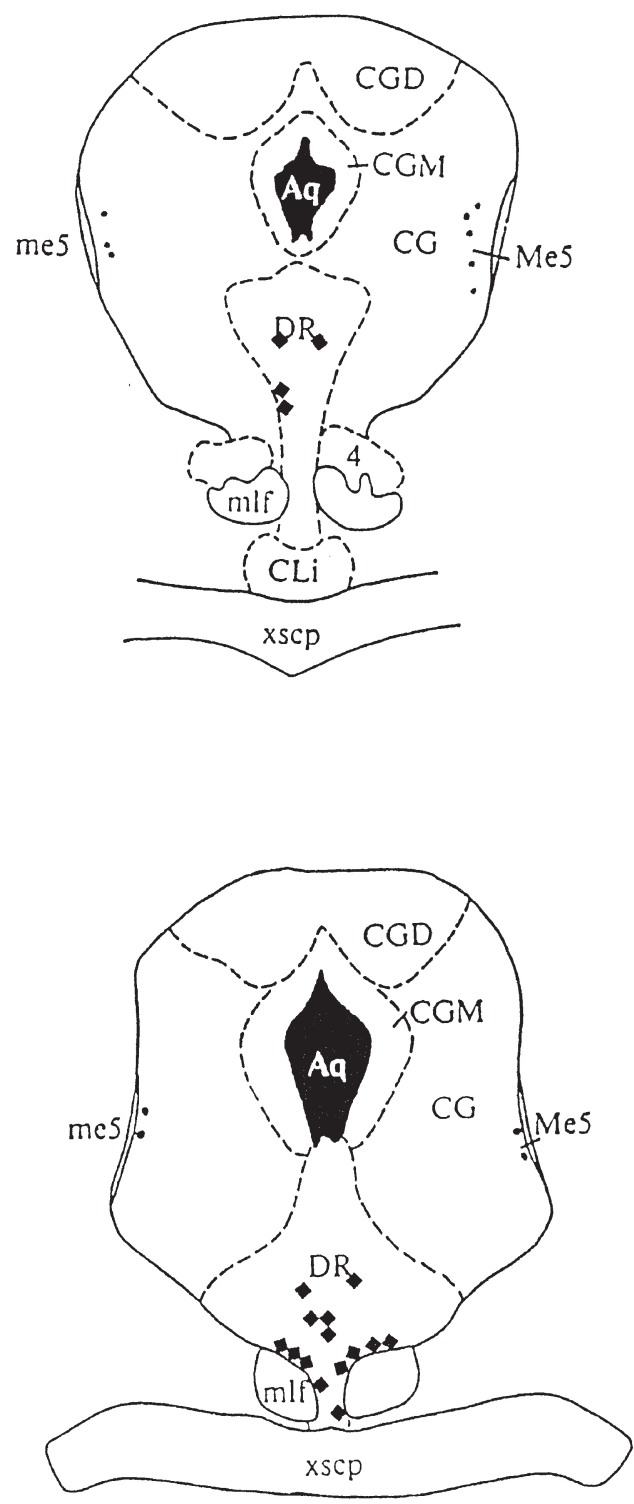

Figure 6. Location of recording sites within the DRN from subjects administered $3.0 \mathrm{ng}$ CRF. The location of recording sites was reconstructed onto plates 29 and 30 from Paxinos and Watson (1986) with diamonds indicating cell location. Abbreviations: cerebral aqueduct $(\mathrm{Aq})$, caudal linear nucleus of the raphe (CLi), central grey $(C G)$, central grey, dorsal (CGD), central grey, medial (CGM), dorsal raphe nucleus (DR), mesencephalic nucleus of the trigeminal nerve (Me5), mesencephalic tract of the trigeminal nerve (me5), medial longitudinal fasciculus (mlf), decussation of the superior cerebellar peduncle (xscp), and trochlear nucleus (4).

pretreatment. Similarly, basal DRN discharge did not differ between the groups administered $3.0 \mathrm{ng}$ CRF with or without DPheCRF $\mathrm{F}_{12-41}$ pretreatment.

Antalarmin (30 mg/kg, i.p.), a CRF-R1-selective antagonist, did not alter DRN discharge rate during the pretreatment period (Figure 7A). However, antalarmin pretreatment completely blocked the inhibition by 3.0 ng CRF 30 min later $[F(11,77)=0.03$, n.s.] (cf. controls
$\mathrm{F}(11,77)=4.00, p<.01)$ (Figure $7 \mathrm{~B})$. A comparison of the effects of CRF on DRN discharge in naive vs. antalarmin-pretreated subjects demonstrates a significant effect of pretreatment $[\mathrm{F}(1,19)=4.98, p<.05]$ and interaction $[\mathrm{F}(11,154)=3.03, p<.01]$.

Antalarmin (30 mg/kg, i.p.) also blocked the inhibitory effect of $10 \mathrm{ng} C R F$ and the transient excitatory effects of $30 \mathrm{ng}$ CRF on DRN discharge. CRF (10 ng) did not decrease DRN discharge rate from baseline in subjects pretreated with antalarmin $[\mathrm{F}(11,55)=0.99$, n.s. $]$ (cf. controls $\mathrm{F}(11,66)=1.97, p<.05)$. CRF (30 ng) did not increase DRN discharge rate from baseline in subjects pretreated with antalarmin $[\mathrm{F}(11,55)=0.59$, n.s. $]$ (cf. controls $\mathrm{F}(11,110)=2.25, p<.05)$.

Figure 7C summarizes the effects of CRF in subjects pretreated with antalarmin vs. controls using the analysis by area under the curve. Using this endpoint, the effect of $3.0 \mathrm{ng}$ CRF was significantly blocked by antalarmin $[\mathrm{F}(1,15)=5.28, p<.05]$.

DPheCRF $_{12-41}(10 \mathrm{ng})$ was administered into the DRN $15 \mathrm{~min}$ prior to intraraphe CRF using a triple barrel micropipette. In contrast to antalarmin, this nonselective CRF antagonist produced a small but statistically significant inhibition of DRN discharge rate $[\mathrm{F}(11,220)=2.06$, $p<.05]$ (Figure 8A). When administered after DPheCRF ${ }_{12-41}, \mathrm{CRF}$ (3 ng) did not decrease discharge rate of seven of eight DRN neurons $[\mathrm{F}(11,66)=1.38$, n.s.] (cf. controls $\mathrm{F}(11,77)=4.00, p<.01$ ) (Figure 8B). A comparison of the effects of CRF on DRN discharge in naive vs. DPheCRF 12-41 $_{1}$-pretreated subjects demonstrates a significant effect of pretreatment $[\mathrm{F}(1,13)=$ $6.28, p<.05]$ and interaction $[\mathrm{F}(11,143)=2.44, p<.01]$. In only one neuron, CRF produced a substantial decrease in DRN discharge rate ( $87 \%$ below baseline).

\section{DISCUSSION}

The immunohistochemical findings in the present study demonstrated a dense innervation of the DRN by CRF that appeared to be topographically organized. The electrophysiological findings were consistent with the hypothesis that endogenous CRF in the DRN could alter activity of putative 5-HT neurons. CRF had predominantly inhibitory effects on DRN discharge and was approximately 300 times more potent when administered into the DRN. The biphasic nature of the CRF doseresponse for effects on DRN discharge mirrored that observed for effects on 5-HT release (Price and Lucki 1998; Price et al. 1998), suggesting that CRF actions on DRN activity impact on 5-HT release in target areas. Finally, sensitivity of CRF effects to both a nonselective CRF antagonist, DPheCRF ${ }_{12-41}$, as well as the CRF-R1 selective antagonist, antalarmin, implicate the CRF-R1 receptor subtype in these CRF-DRN interactions. 
A

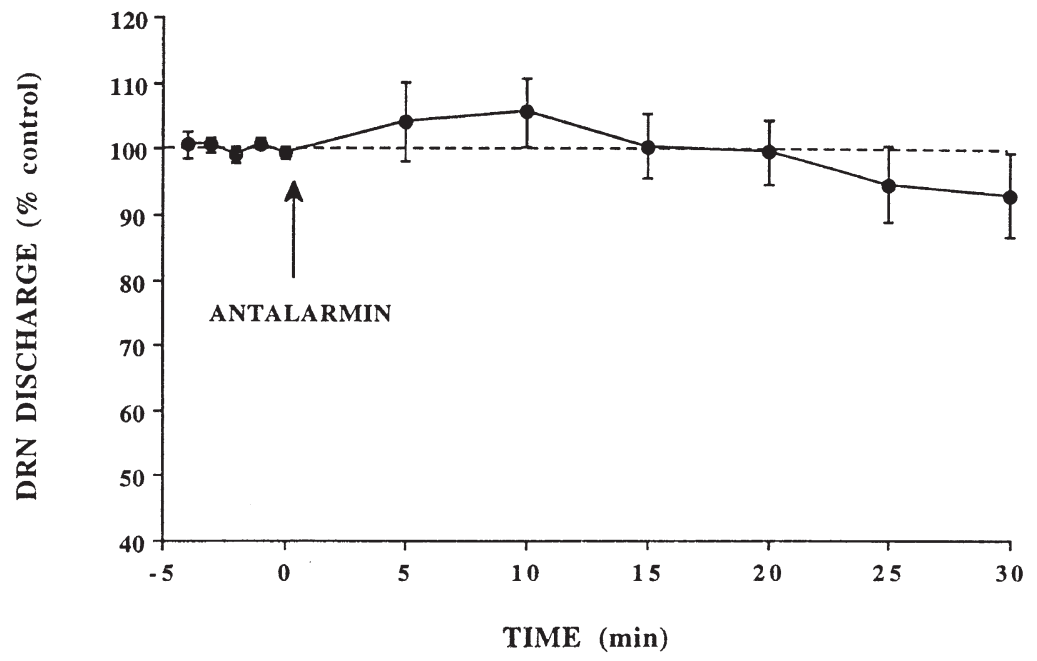

B

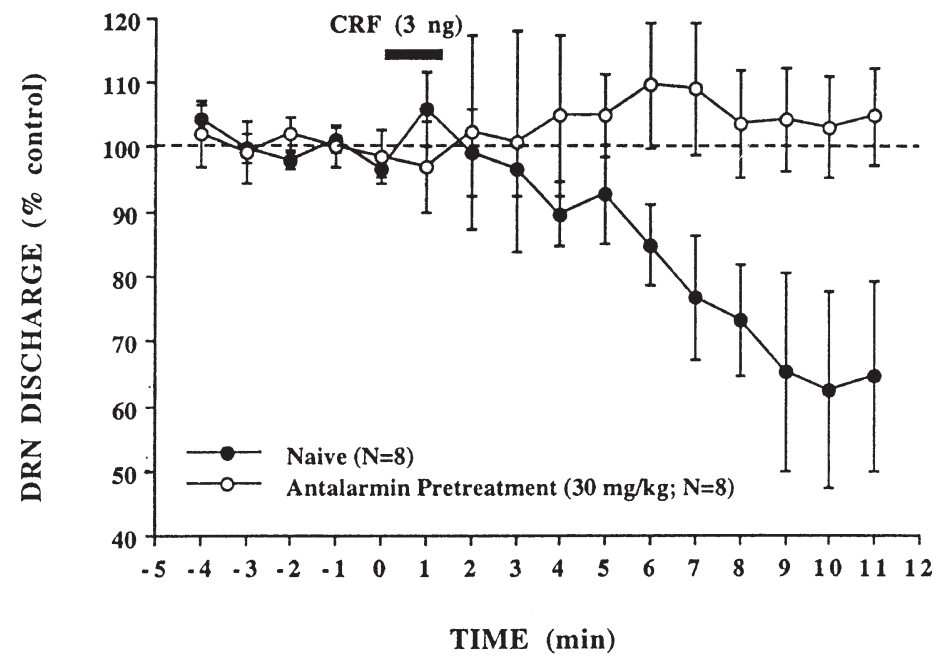

C

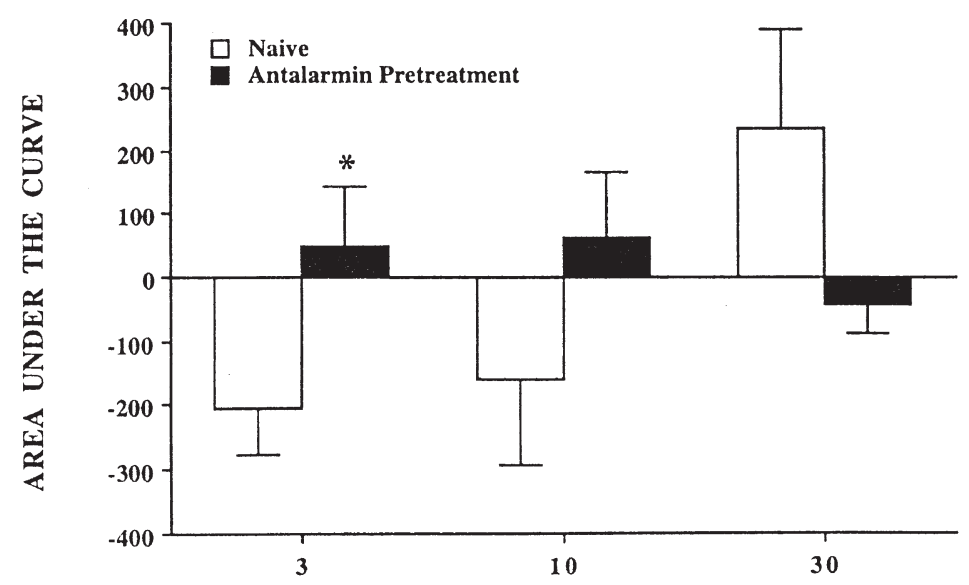

Figure 7. Effect of antalarmin on responses of DRN neurons to intraraphe infusion of CRF. (A) The abscissa indicates the time before and after administration of antalarmin (30 $\mathrm{mg} / \mathrm{kg}$, i.p.), indicated by the arrow, which occurred at 0 . The ordinate indicates the mean discharge rate expressed as a percentage of the mean rate determined over $5 \mathrm{~min}$ prior to injection. (B) Time course of the effect of CRF (3.0 ng) on DRN discharge in naive (closed circles) or antalarmin (open circles) pretreated subjects. Abscissa and ordinate as in (A). (C) Bars represent the area under the curve describing the time-effect relationship to illustrate the overall effect of each dose of CRF in naive or pretreated subjects on DRN neuronal discharge. Data presented are mean \pm 1 S.E.M. values. The asterisk indicates a significant difference from naive controls by unpaired Student's $t$-test $(p<.05)$.

DOSE CRF (ng) 
A

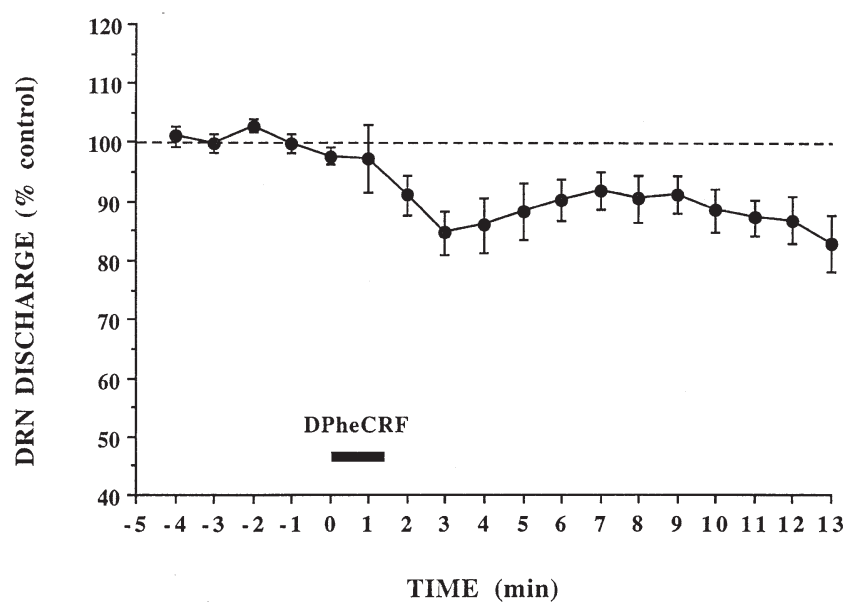

B

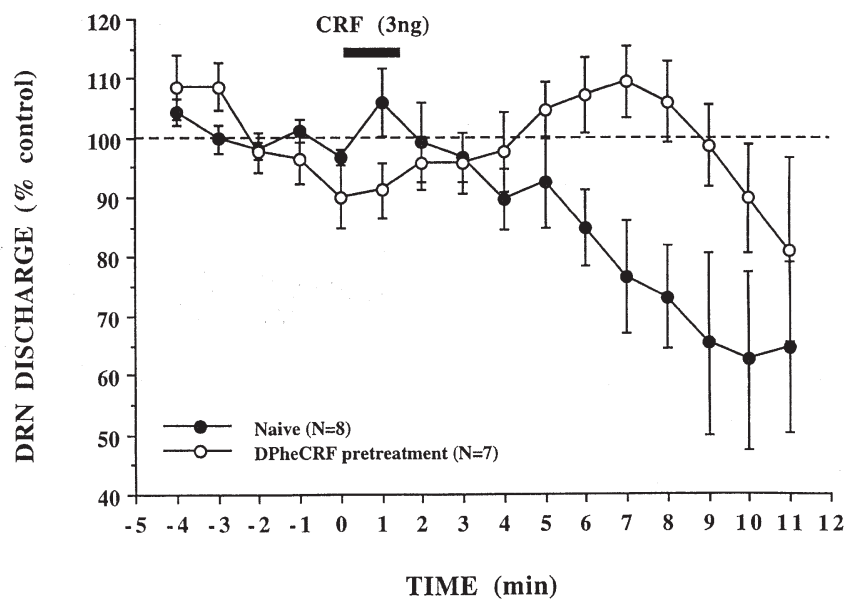

Figure 8. Effect of DPheCRF $\mathrm{DL}_{12-41}$ (10 ng, intraraphe) on responses of DRN neurons to intraraphe infusion of CRF $(3.0 \mathrm{ng})$. (A) The abscissa indicates the time before and after microinfusion of $\mathrm{DPheCRF}_{12-41}$, indicated by the bar, which began at 0 . The ordinate indicates the mean discharge rate expressed as a percentage of the mean rate determined over $5 \mathrm{~min}$ prior to injection. (B) Time course of the effect of CRF on DRN discharge in naive (closed circles) or DPheCRF D $_{12-41}$ (open circles) pretreated subjects. Data presented are mean \pm 1 S.E.M. values.
Previous immunohistochemical studies describing the distribution of CRF fibers in rat brain reported the DRN as one nucleus in which CRF-IR fibers were visualized (Sakanaka et al. 1987; Swanson et al. 1983). The present study confirmed these findings and further described a topographical organization of this innervation. The various subnuclei of the DRN differ in their morphology, afferent inputs and efferent targets, suggesting that they may be functionally differentiated (Molliver 1987; Peyron et al. 1998; Tork 1990).

The significance of a topographical arrangement of CRF innervation lies in the possibility that different sets of CRF neurons project to specific subnuclei of the DRN that have functionally different forebrain targets. For example, the lateral wings receive diverse afferent inputs (Peyron et al. 1998) and provide 5-HT innervation to the thalamus (De Olmos and Heimer 1980; Waterhouse et al. 1993), nucleus accumbens (Van Bockstaele et al. 1993), lateral geniculate nucleus (Pasquier and Villar 1982), and superior colliculus (Waterhouse et al. 1993). The ventromedial DRN receives more restricted afferent input (Peyron et al. 1998) and is a source of 5-HT innnervation to the cortex (Datiche et al. 1995; Waterhouse et al. 1993, 1986; Kohler and Steinbusch 1982), septum (Kohler et al. 1982), hippocampus (Kohler and Steinbusch 1982), and ventral tegmental area (Simon et al. 1979). This arrangement would allow specific stimuli to differentially alter 5-HT release in selective targets of the DRN through activation of selective CRF afferents.

CRF had predominantly inhibitory effects on DRN neurons. Inhibitory effects of CRF in the brain are not unique to the DRN as they have been demonstrated in neurons of the thalamus, lateral septum (Eberly et al. 1983), the paraventricular nucleus of the hypothalamus (Siggins et al. 1985), and the central nucleus of the amygdala (Rainnie et al. 1992). Although the majority of DRN neurons were inhibited by CRF, there was substantial variability in the magnitude and time course of the responses and this was most apparent with i.c.v. administered CRF. This is in contrast to the effects of i.c.v. CRF on LC neurons, which are more consistent in re- 
sponse and time course (Curtis et al. 1997). A potential factor in the variability of DRN responses to i.c.v. CRF relates to the wide range in distance of neurons from the ventricular surface. Thus, periventricular DRN cells would be exposed to a higher concentration of a given dose of i.c.v. administered CRF (which is less likely to be inhibitory) compared to cells located in the intrafasicular region, which can be up to $1.5 \mathrm{~mm}$ from the ventricular surface. Indeed, our results suggest more consistent inhibition by CRF of ventromedial DRN neurons.

An additional factor that can contribute to variability in response to CRF after either i.c.v. or local administration is the cellular heterogeneity of the DRN, which contains a substantial number of non-5-HT neurons and interneurons (Jacobs and Azmitia 1992), in contrast to the more homogeneous LC (Foote et al. 1983). To minimize this confound, experiments involving intraraphe administration of CRF were restricted to cells located in the ventromedial region of the DRN, the location of the largest cluster of 5-HT cells (Molliver 1987). Finally, the presence of both CRF-R1 and CRF-R2 receptor subtypes in the DRN (Chalmers et al. 1995) which may be located on different cellular elements (eg., interneurons vs. 5-HT neurons) and may have opposing effects could contribute to the complex effects of CRF in the DRN.

It is noteworthy that responses of putative 5-HT DRN neurons to other peptides showed a similar heterogeneity even in in vitro slice preparations. For example, the percentage of DRN neurons in the ventromedial region vs. the dorsal region and lateral wings that were most responsive (excited) to neurotensin (ventromedial region: 64\%; dorsal/lateral wings: $23 \%$ ) (Jolas and Aghajanian 1996) was similar to the percentages of neurons in these subnuclei that were inhibited by CRF in the present study (ventromedial region: $61 \%$; dorsal/ lateral wings: $46 \%$ ). These investigators noted that the pattern of neurotensin responses corresponded with the density of neurotensin receptors within the DRN (Jennes et al. 1982; Uhl et al. 1979). Such a differential distribution of CRF receptor subtypes within the DRN may also exist, although this has yet to be investigated.

Many of the same factors that could account for variation in neuronal responses to a single dose of CRF could also contribute to the biphasic nature of the CRF dose-response curve. Although CRF receptor subtypes identified in the DRN thus far have similar cellular mechanisms (i.e., activation of adenylate cyclase via G-protein) they may mediate opposing effects, particularly if they are located on different neurons (eg., 5-HT neurons vs. $\gamma$-aminobutyric acid (GABA) interneurons). It is possible that CRF-R1 and CRF-R2 receptors mediate inhibition and excitation, respectively.

Ovine CRF (the peptide used in these studies) is 8 times more potent at the CRF-R1 subtype (Lovenberg et al. 1995), consistent with an inhibitory effect of low doses and a loss of the effect at higher doses. This could also explain the small, but significant inhibition in DRN discharge rate associated with intraraphe administration of DPheCRF $\mathrm{D}_{12-41}$, which is slightly more potent at the predominant CRF-R2 receptors (Primus et al. 1997). However, in this hypothetical situation, a pure CRF-R1 antagonist would be expected to prevent inhibition associated with CRF-R1 receptors and unmask activation by CRF acting at CRF-R2 receptors. In contrast, antalarmin was equally effective in antagonizing CRF at all doses. Unraveling these complex dose-related effects of CRF on DRN discharge and 5-HT release will require more selective agonists and antagonists at both receptor subtypes (which are not presently available). Additionally, a better understanding of the cellular distribution of these receptor subtypes in the DRN will be necessary.

The present electrophysiological findings mirror the effects of CRF on 5-HT extracellular levels (as measured by in vivo microdialysis) in the striatum and lateral septum (Price and Lucki 1998; Price et al. 1998). Thus, CRF (administered i.c.v.) decreased extracellular 5-HT in striatum and lateral septum at low doses and increased extracellular 5-HT (striatum) or had no effect (lateral septum) at higher doses. Similar effects of CRF on 5-HT release in two different terminal regions of the DRN are consistent with the possibility that CRF actions within the DRN are involved in the neurochemical effects.

Taken with preliminary studies demonstrating that CRF administered into the DRN has similar effects on 5-HT extracellular levels in the lateral septum (Price and Lucki 1999), the present electrophysiological findings support this hypothesis. Parallel effects on DRN discharge and 5-HT terminal release has also been shown for other compounds such as the $5-\mathrm{HT}_{1 \mathrm{~A}}$ agonist 8-OH-DPAT, which decreases both DRN discharge and terminal 5-HT release (Crespi et al. 1990), 5- $\mathrm{HT}_{2}$ agonists (Wright et al. 1990), and serotonin-selective reuptake inhibitors (Romero et al. 1996). Furthermore, parallel effects of CRF on LC discharge and terminal norepinephrine release have been demonstrated (Page and Abercrombie 1999; Curtis et al. 1997; Smagin et al. 1995). Thus, the effects of CRF on DRN discharge reported here are likely translated to changes in 5-HT release in forebrain terminal regions.

Functionally, these studies indicate a potential role for CRF in mediating the effects of stress on the 5-HT system. In addition to initiating the hormonal response to stress in the periphery (Vale et al. 1983), CRF is anatomically positioned to mediate the effects of stress on neurotransmitter systems in a number of different brain regions (Sakanaka et al. 1987; Swanson et al. 1983). The high density of CRF-IR fibers noted in the DRN indicate that CRF is particularly well situated to have an impact on the 5-HT system when it is released during stress. The 5-HT system has been shown to respond to a variety of stressors (for review, see Chaouloff 1993; Stanford 1993). For example, earlier studies using in vivo mi- 
crodialysis techniques have demonstrated that $5-\mathrm{HT}$ is released from terminals in a stressor- and region-specific manner (Kirby et al. 1995, 1997).

It is noteworthy that one particular stressor, forced swimming, was associated with decreases of extracellular 5-HT in several brain regions including the DRN, lateral septum, and amygdala (Chou et al. 1995; Kirby et al. 1995). Swim-induced decreases in 5-HT release were similar in magnitude and time course to those decreases observed in the lateral septum after CRF administration (Price and Lucki 1998). Importantly, the effects of forced swimming on lateral septum 5-HT were prevented by pretreatment with $\mathrm{DPheCRF}_{12-41}$ (Price and Lucki 1998), implicating endogenous CRF in these effects. More recent work has shown that the 5-HT response to CRF is attenuated in both cell body (Kirby and Valentino 1998) and terminal regions (Price and Lucki 1998) 24 hours following exposure to forced swimming, when rats typically exhibit behavioral deficits that are sensitive to antidepressant treatment (Porsolt et al. 1977, 1978). Taken together, these results provide support for the hypothesis that endogenous CRF mediates the effects of forced swimming on the 5-HT system and may play a larger role as a link between stress and the 5-HT system.

On another level, both CRF and the 5-HT system have been shown to be dysfunctional in a number of stress-related psychiatric disorders such as depression (for review, see Caldecott-Hazard et al. 1991; Stokes and Sikes 1987). Thus, in addition to linking stress and the 5-HT system, CRF may play a role in the dysfunctions of the 5-HT system during depression. Towards this end, CRF and the interactions between CRF and the 5-HT system may be important targets for novel pharmacological treatments for depression.

\section{ACKNOWLEDGMENTS}

This work was supported by PHS grants MH 58250, an NRSA (MH 12274) to L.G.K. and a Research Scientist Development Award (MH 00840) to R.J.V. The authors wish to thank Dr. Jean Rivier (Clayton Foundation Laboratories for Peptide Biology, The Salk Institute, La Jolla, CA) for the generous gifts of CRF and DPheCRF ${ }_{12-41}$, Dr. Wylie Vale (The Salk Institute) for the gift of CRF antiserum, and finally George Chrousos, M.D. (Developmental Endocrinology Branch, NICHD, NIH), Elizabeth Webster, Ph.D., Kamal Habib, M.D., and Philip Gold, M.D. (Clinical Neuroendocrinology Branch, NIMH, NIH) for insightful comments and suggestions regarding the use of antalarmin.

\section{REFERENCES}

Baraban JM, Aghajanian GK (1980): Suppression of serotonergic neuronal firing by $\alpha$-adrenoceptor antagonists: Evidence against GABA mediation. Eur J Pharmacol
66:287-294

Caldecott-Hazard S, Morgan DG, DeLeon-Jones F, Overstreet DH, Janowsky D (1991): Clinical and biochemical aspects of depressive disorders. II. Transmitter/receptor theories. Synapse 9:251-301

Chalmers DT, Lovenberg TW, De Souza EB (1995): Localization of novel corticotropin-releasing factor receptor (CRF2) mRNA expression to specific subcortical nuclei in rat brain: Comparison with CRF1 receptor mRNA expression. J Neurosci 15:6340-6350

Chaouloff F (1993): Physiopharmacological interactions between stress hormones and central serotonergic systems. Brain Res Rev 18:1-32

Chou JM, Kirby LG, Lucki I (1995): Effect of forced swimming stress on extracellular levels of 5-HT in the dorsal raphe nucleus of the rat. Soc Neurosci Abs 21:2058

Crespi F, Garratt JC, Sleight AJ, Marsden CA (1990): In vivo evidence that 5-hydroxytryptamine (5-HT) neuronal firing and release are not necessarily correlated with 5-HT metabolism. Neuroscience 35:139-144

Curtis AL, Florin-Lechner SM, Pavcovich LA, Valentino RJ (1997): Activation of the locus coeruleus noradrenergic system by intracoerulear microinfusion of corticotropin-releasing factor: Effects on discharge rate, cortical norepinephrine levels and cortical electroencephalographic activity. J Pharmacol Exp Ther 281:163-172

Curtis AL, Grigoradis D, Page ME, Rivier J, Valentino RJ (1994): Pharmacological comparison of two corticotropin-releasing factor antagonists: In vivo and in vitro studies. J Pharmacol Exp Ther 268:359-365

Datiche F, Luppi P-H, Cattarelli M (1995): Serotonergic and non-serotonergic projections from the raphe nuclei to the piriform cortex in the rat: A cholera toxin B subunit $(\mathrm{CTb})$ and 5-HT immunohistochemical study. Brain Res 671:27-37

De Olmos J, Heimer L (1980): Double and triple labeling of neurons with fluorescent substances: The study of collateral pathways in the ascending raphe system. Neurosci Lett 19:7-12

De Souza EB, Insel TR, Perrin MH, Rivier J, Vale WW, Kuhar MJ (1985): Corticotropin-releasing factor receptors are widely distributed within the rat central nervous system: An autoradiographic study. J. Neurosci 5:31893203

Eberly LB, Dudley CA, Moss RL (1983): Iontophoretic mapping of corticotropin-releasing factor (CRF) sensitive neurons in the rat forebrain. Peptides 4:837-841

Foote SL, Bloom FE, Aston-Jones G (1983): Nucleus locus coeruleus: New evidence of anatomical and physiological specificity. Physiol Rev 63:844-914

Jacobs BL, Azmitia EC (1992): Structure and function of the brain serotonin system. Physiol Rev 72:165-228

Jennes L, Stumpf WE, Kalivas PW (1982): Neurotensin: Topographical distribution in rat brain by immunohistochemistry. J Comp Neurol 210:211-224

Jolas T, Aghajanian GK (1996): Neurotensin excitation of serotonergic neurons in the dorsal raphe nucleus of the rat in vitro. Eur J Neurosci 8:153-161

Kirby LG, Allen AR, Lucki I (1995): Regional differences in the effects of forced swimming on extracellular levels of 
5-hydroxytryptamine and 5-hydroxyindoleacetic acid. Brain Res 682:189-196

Kirby LG, Chou-Green JM, Davis K, Lucki I (1997): The effects of different stressors on extracellular 5-hydroxytryptamine and 5-hydroxyindoleacetic acid. Brain Res 760:218-230

Kirby LG, Valentino RJ (1998): Activity of dorsal raphe nucleus (DRN) neurons in response to corticotropinreleasing factor (CRF): Possible regulation by swim stress. Soc Neurosci Abs 24:2048

Kohler C, Chan-Palay V, Steinbusch H (1982): The distribution and origin of serotonin-containing fibers in the septal area: A combined immunohistochemical and fluorescent retrograde tracing study in the rat. J Comp Neurol 209:91-111

Kohler C, Steinbusch H (1982): Identification of serotonin and non-serotonin-containing neurons of the mid-brain raphe projecting to the entorhinal area and the hippocampal formation. A combined immunohistochemical and fluorescent retrograde tracing study in the rat brain. Neurosci 7:951-975

Lavicky J, Dunn AJ (1993): Corticotropin-releasing factor stimulates catecholamine release in hypothalamus and prefrontal cortex in freely moving rats as assessed by microdialysis. J Neurochem 60:602-612

Lechner S, Curtis A, Brons R, Valentino R (1997): Locus coeruleus activation by colon distention: Role of corticotropin-releasing factor and excitatory amino acids. Brain Res 756:114-124

Lovenberg TW, Liaw CW, Grigoriadis DE, Clevenger W, Chalmers DT, De Souza EB, Oltersdorf T (1995): Cloning and characterization of a functionally distinct corticotropin-releasing factor receptor subtype from rat brain. Proc Natl Acad Sci 92:836-840

Molliver ME (1987): Serotonergic neuronal systems: What their anatomic organization tells us about function. J Clin Psychopharmacol 7:3S-23S

Page ME, Abercrombie ED (1999): Discrete local application of corticotropin-releasing factor increases locus coeruleus discharge and extracellular norepinephrine in rat hippocampus. Synapse 33:304-313

Pasquier DA, Villar MJ (1982): Specific serotonergic projections to the lateral geniculate body from the lateral cell groups of the dorsal raphe nucleus. Brain Res 249:142146

Paxinos G, Watson C (1986): The Rat Brain in Stereotaxic Coordinates. North Ryde, Academic Press

Peyron C, Petit J-M, Rampon C, Jouvet M, Luppi P-H (1998): Forebrain afferents to the rat dorsal raphe nucleus demonstrated by retrograde and anterograde tracing methods. Neuroscience 82:443-468

Porsolt RD, Anton G, Blavet N, Jalfre M (1978): Behavioral despair in rats: A new model sensitive to antidepressant treatments. Eur J Pharmacol 47:379-391

Porsolt RD, Le Pinchon M, Jalfre M (1977): Depression: A new animal model sensitive to antidepressant treatments. Nature 266:730-732

Potter E, Sutton S, Donaldson C, Chen R, Perrin M, Lewis K, Sawchenko PE, Vale W (1994): Distribution of corticotropin-releasing factor receptor mRNA expression in the rat brain and pituitary. Proc Natl Acad Sci 91:8777-8781
Price M, Lucki I (1998): Regulation of serotonin (5-HT) release in the lateral septum by forced swimming involves corticotropin-releasing factor (CRF). Soc Neurosci Abs 24:2048

Price ML, Curtis AL, Kirby LG, Valentino RJ, Lucki I (1998): Effects of corticotropin-releasing factor on brain serotonergic activity. Neuropsychopharmacology 18:492-502

Price ML, Lucki I (1999): Corticotropin-releasing factor (CRF) regulates serotonin (5-HT) release at the dorsal raphe nucleus. Soc Neurosci Abs 25:2221

Primus RJ, Yevich E, Baltazar C, Gallager DW (1997): Autoradiographic localization of CRF1 and CRF2 binding sites in adult rat brain. Neuropsychopharmacology 17:308-316

Rainnie DG, Fernhout BJH, Shinnick-Gallagher P (1992): Differential actions of corticotropin releasing factor on basolateral and central amygdaloid neurons, in vitro. J Pharmacol Exp Ther 263:846-858

Romero L, Bel N, Artigas F, de Montigny C, Blier P (1996): Effect of pindolol on the function of pre- and postsynaptic 5-HT1A receptors: In vivo microdialysis and electrophysiological studies in the rat brain. Neuropsychopharmacology 15:349-360

Sakanaka M, Shibasaki T, Lederes K (1987): Corticotropinreleasing factor-like immunoreactivity in the rat brain as revealed by a modified cobalt-glucose oxide-diaminobenzidene method. J Comp Neurol 260:256-298

Siggins GR, Gruol DL, Aldenhoff J, Pittman Q (1985): Electrophysiological actions of corticotropin-releasing factor in the central nervous system. Fed Proc 44:237-242

Simon H, Le Moal M, Calas A (1979): Efferents and afferents of the ventral tegmental-A10 region studied after local injection of $[3 \mathrm{H}]$ leucine and horseradish peroxidase. Brain Res 178:17-40

Smagin GN, Swiergiel AH, Dunn AJ (1995): Corticotropinreleasing factor administered into the locus coeruleus, but not the parabrachial nucleus, stimulates norepinephrine release in the prefrontal cortex. Brain Res Bull 36:71-76

Stanford SC (1993): Mononamines in response and adaptation to stress. In Stanford SC, Salmon P (eds), Stress: From Synapse to Syndrome. New York, Academic Press, pp 281-331

Stokes PE, Sikes CR (1987): Hypothalamic-pituitary-adrenal axis in affective disorders. In Meltzer HY (ed) Psychopharmacology: The Third Generation of Progress, 3rd ed. New York, Raven Press, pp 589-607

Swanson LW, Sawchenko PE, Rivier J, Vale W (1983): Organization of ovine corticotropin-releasing factor immunoreactive cells and fibers in rat brain: An immunohistochemical study. Neuroendocrinology 36:165-186

Tork I (1990): Anatomy of the serotonergic system. Ann N Y Acad Sci 600:9-35

Uhl GR, Goodman RR, Snyder SH (1979): Neurotensin-containing cell bodies, fibers and nerve terminals in the brain stem of the rat: Immunohistochemical mapping. Brain Res 167:77-91

Vale W, Rivier C, Brown MR, Spiess J, Koob G, Swanson L, Bilezikjian L, Bloom F, Rivier J (1983): Chemical and biological characterization of corticotropin-releasing factor. Rec Prog Horm Res 39:245-270 
Valentino RJ, Foote SL, Aston-Jones G (1983): Corticotropinreleasing factor activates noradrenergic neurons of the locus coeruleus. Brain Res 270:363-367

Van Bockstaele EJ, Biswas A, Pickel VM (1993): Topography of serotonin neurons in the dorsal raphe nucleus that send axon collaterals to the rat prefrontal cortex and nucleus accumbens. Brain Res 624:188-198

Waterhouse BD, Border B, Wahl L, Mihailoff GA (1993): Topographic organization of rat locus coeruleus and dorsal raphe nuclei: Distribution of cells projecting to visual system structures. J Comp Neurol 336:345-361

Waterhouse BD, Mihailoff GA, Baack JC, Woodward DJ (1986): Topographical distribution of dorsal and median raphe neurons projecting to motor, sensorimotor, and visual cortical areas in the rat. J Comp Neurol 249:460-476

Wright IK, Garratt JC, Marsden CA (1990): Effects of a selective 5-HT2 agonist, DOI, on 5-HT neuronal firing in the dorsal raphe nucleus and 5-HT release and metabolism in the frontal cortex. Br J Pharmacol 99:221-222 